\title{
The Biology Underlying Abnormalities of Tooth Number in Humans
}

\author{
Juuri, E.
}

2017-10

Juuri , E \& Balic , A 2017 , ' The Biology Underlying Abnormalities of Tooth Number in

Humans ' , Journal of Dental Research , vol. 96 , no. 11 , pp. 1248-1256 . https://doi.org/10.1177/002203451772015

http://hdl.handle.net/10138/298046

https://doi.org/10.1177/0022034517720158

publishedVersion

Downloaded from Helda, University of Helsinki institutional repository.

This is an electronic reprint of the original article.

This reprint may differ from the original in pagination and typographic detail.

Please cite the original version. 


\title{
The Biology Underlying Abnormalities of Tooth Number in Humans
}

Journal of Dental Research 2017, Vol. 96(II) 1248-1256

(C) International \& American Associations for Dental Research 2017 Reprints and permissions: sagepub.com/journalsPermissions.nav DOI: $10.1177 / 0022034517720158$

journals.sagepub.com/home/jdr

\author{
E. Juuri' and A. Balic ${ }^{2}$
}

\begin{abstract}
In past decades, morphologic, molecular, and cellular mechanisms that govern tooth development have been extensively studied. These studies demonstrated that the same signaling pathways regulate development of the primary and successional teeth. Mutations of these pathways lead to abnormalities in tooth development and number, including aberrant tooth shape, tooth agenesis, and formation of extra teeth. Here, we summarize the current knowledge on the development of the primary and successional teeth in animal models and describe some of the common tooth abnormalities in humans.
\end{abstract}

Keywords: primary dentition, permanent dentition, successional tooth formation, tooth replacement, tooth agenesis, supernumerary tooth formation

\section{Development of the Primary Dentition}

Tooth development initiates around the sixth week of gestation as morphologically distinct thickening of the oral ectoderm called dental lamina (Fig. 1; Ooë 1981). This uniform strip of ectodermal cells indicates the location of the future dentition. Studies on animal models, mainly mice, have shown that it is characterized by the expression of several markers, including Pitx2, the transcription factor most specific for the dental epithelium, as well as Foxi3, Shh, Dlx2, Lef1, and p63 (Balic and Thesleff 2015). Only lack of p63 leads to dental lamina arrest, demonstrating a functional role for $p 63$ in developmental progression of dental lamina (Laurikkala et al. 2006).

In the following days, dental lamina invaginates into the underlying mesenchyme, generating tooth placodes, which mark the onset of individual tooth development - namely, the first incisor, canine, and first molar in the primary dentition (Fig. 2; Ooë 1981). These morphologically distinct structures are composed of the basal cell layer and multilayered suprabasal cells and express Pitx2, Foxi3, and Sp6 (Nakamura et al. 2004; Balic and Thesleff 2015). Epithelial cells within the placode progressively proliferate and form the bud-shaped structure surrounded by the condensed neural crest-derived dental mesenchyme.

In the ensuing steps, the epithelium folds into a cap-like structure, which further extends apically to form a bell-like structure that resembles the shape of the future tooth crown. Epithelial morphogenesis of primary teeth is regulated by signaling centers: clusters of nonproliferative cells characterized by the localized expression of several genes, including $p 21$, Edar, Dkk4, and Fgf20, within the tooth epithelium (Balic and Thesleff 2015). Three signaling centers form during tooth development (Fig. 2). The first is the initiation knot, which forms in the placodes and governs the budding of the dental epithelium and the condensation of the adjacent neural crestderived mesenchyme (Ahtiainen et al. 2016). The second is the primary enamel knot, which appears at the tip of the newly formed bud and governs tooth crown development and formation of secondary enamel knots, a third generation of signaling centers that fine-tune crown morphogenesis by determining the sites of cusps.

In the primary dentition, teeth within the same class are serially added in the anterior-posterior direction (Fig. 2). Dental lamina extends posteriorly at the time that the predecessor tooth reaches the cap stage and buds, generating the successor tooth germ that develops similarly to its predecessor (Ooë 1981).

\section{Development of the Permanent Dentition}

The most extensive and detailed morphological analysis of development of the human permanent dentition is found in Ooë (1981) and more recent work (Hovorakova et al. 2007; Peterkova et al. 2014). However, very little is known of molecular and cellular mechanisms governing this process. As summarized by Ooë, the primordia of the first permanent tooth germs are observed between the 10th and 13th weeks of gestation.

Permanent dentition forms through successional tooth formation, which refers to replacement and serial addition of

'Department of Oral and Maxillofacial Diseases, Faculty of Medicine, University of Helsinki, Helsinki, Finland

${ }^{2}$ Research Program in Developmental Biology, Institute of Biotechnology, University of Helsinki, Helsinki, Finland

\section{Corresponding Author:}

A. Balic, Research Program in Developmental Biology, Institute of Biotechnology, University of Helsinki, Viikinkaari 5D, Helsinki 000I4, Finland.

Email: anamaria.balic@helsinki.fi 
teeth. In both cases, the successional tooth is formed from the extension of dental lamina of the predecessor tooth, when the preceding tooth is in the early cap stage (Juuri et al. 2013). These 2 processes are believed to be similar, particularly considering that in both cases the successional tooth forms from Sox $2^{+}$cells (Juuri et al. 2013). However, the orientation of the dental lamina extension and the direction of the new tooth formation are different. Replacement teeth are initiated from the lingual extension of dental lamina, called successional lamina, and develop in vertical direction (Fig. 3). Serially added teeth, such as molars, derive from the horizontal and posterior extension of the dental lamina, referred to as continual lamina, burrowing under the oral epithelium (Figs. 2, 3; Ooë 1981). The onset of the new generation of teeth initiates separation of the dental lamina from the oral epithelium. Unlike continual lamina, the successional lamina loses its connection to oral epithelium through both apoptosis and epithelial-to-mesenchymal transition mechanisms (Ooë 1981; Stembírek et al. 2010).

During tooth morphogenesis, primary tooth germs are interconnected by interdental lamina, the epithelial sheet of variable depth and thickness, which forms through downgrowth of the dental lamina. Interdental lamina does not participate in the formation of new teeth. Interestingly, gene expression analyses on diphyodont ferret and minipig have demonstrated that the interdental and successional laminae share similar molecular characteristics, including diffused expression of Foxi3 and Pitx2; asymmetric distribution of Sox2 and Bmp4, located at the lingual side, and FZD6, a WNT pathway receptor, expressed in the buccal/labial side (Järvinen et al. 2009; Juuri et al. 2013; Jussila et al. 2014; Putnova et al. 2017). The only gene expressed in a distinct pattern is Sostdcl, which is expressed on the lingual side in the successional lamina (Järvinen et al. 2009) in contrast to the labial location in the interdental lamina. Overall, the gene expression pattern indicates that the tooth-forming capacity identified by expression of Pitx2 is present in all tooth epithelial laminae. Differences in the distribution of Sostdcl, the mutation of which leads to supernumerary teeth in mice, imply active participation of Sostdcl in successional tooth formation. Most importantly, they suggest the presence of inhibitory signals, most likely residing in the mesenchyme, which block tooth initiation from the interdental lamina.

\section{Molecular and Cellular Mechanisms Regulating Successional Tooth Formation}

The mouse has been used extensively to study the molecular regulation of tooth development which is conserved among animal species. It has also been used to study serial addition of teeth in the same class. However, mice do not replace their teeth; therefore, other animal models are used to study the molecular mechanisms governing tooth replacement. These include diphyodont mammals with heterodont dentitions, such as the ferret, minipig, and fruit bat, as well as other models that replace their teeth (shrews, reptiles, and fish), which have been utilized to study gene expression patterns related to the tooth

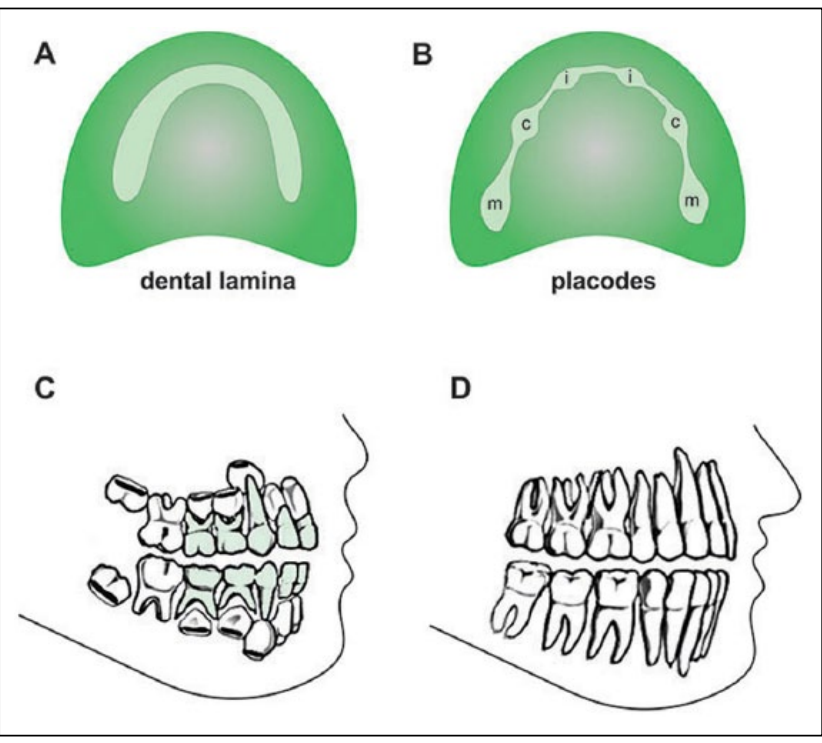

Figure I. Initiation of tooth development. (A) Tooth development starts with the thickening of the oral epithelium named dental lamina or odontogenic band, which indicates the location of the future dentition. (B) Dental placodes, which are invaginations of dental lamina into the underlying mesenchyme, mark the onset of the individual tooth development and are interconnected with the dental lamina. (C) Primary dentition (light green) of a 6-y-old and (D) permanent dentition. Humans, like most other mammals, are diphyodonts: they have 2 successive sets of teeth-primary and permanent dentitions. Both dentitions are heterodont, consisting of morphologically distinct types of teeth. Primary dentition consists of 20 teeth: 2 incisors, a canine, and 2 molars in each jaw quadrant. In permanent dentition, addition of 3 posterior molars per quadrant raises the tooth count to 32 . c, canine placode; i, incisor placode; $m$, primary molar placode. Panels $C$ and $D$ : adapted from Encyclopedia Britannica.

replacement (Huysseune and Witten 2006; Järvinen et al. 2008; Järvinen et al. 2009; Stembírek et al. 2010; Richman and Handrigan 2011; Jussila et al. 2014; Martin et al. 2016; Popa et al. 2016). While these models provide valuable insights into the molecular and cellular mechanisms underlying successional tooth development, functional experiments are mostly lacking. Furthermore, in some fish models, tooth replacement is different from mammalian diphyodonts in that the teeth form directly from a thickening of the outer enamel epithelium and not from successional lamina (Jernvall and Thesleff 2012). In contrast to fish, reptiles replace their teeth through successional dental lamina and have provided significant progress in our understanding of the tooth replacement process (Handrigan and Richman 2010; Richman and Handrigan 2011; Gaete and Tucker 2013).

Successional tooth formation requires stem cells to generate new tissues. Tooth epithelial stem cells were first identified in the continuously growing mouse incisors as label-retaining cells. Later studies have shown that they also express many stem cell markers, including Sox2, and that they generate all epithelial lineages in teeth (Balic and Thesleff 2015). In the reptilian dental lamina, expression of stem cell markers Sox2, $L g r 5, D k k 3$, and $\lg f p 5$ is restricted to the lingual side and is associated with slow-cycling and label-retaining cells (Handrigan 


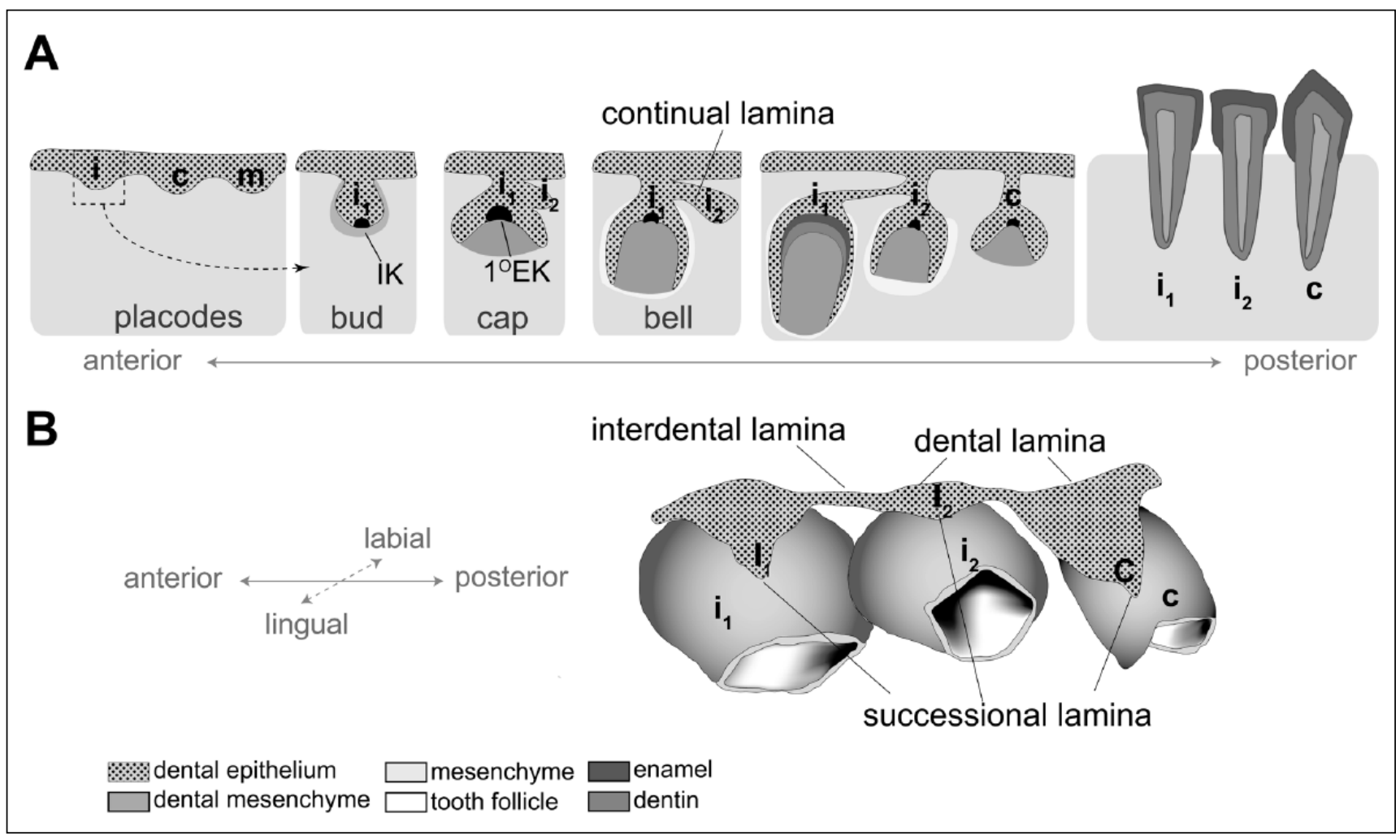

Figure 2. Development of the primary dentition. (A) Stages of primary tooth development. Initially, only 3 placodes are seen in each jaw quadrant: incisor, canine, and molar. Second tooth in the same tooth family forms through serial addition, depicted for the second primary incisor. Continual lamina forms around cap stage, and it will generate the second primary incisor in the following steps. (B) Reconstruction of the human primary teeth (incisors and the canine) adapted from Ooë (198I). Primary tooth germs are interconnected with interdental lamina, and initiation of permanent teeth from successional lamina is depicted. $I^{\circ}$ EK, primary enamel knot; $c$, primary canine; $C$, permanent canine; $i_{1}$, first primary incisor; $i_{2}$, second primary incisor; I, first permanent incisor; $I_{2}$, second permanent incisor; IK, initiation knot.

et al. 2010; Juuri et al. 2013). Their location corresponds to the site of formation of successional lamina. In addition, a functional study based on genetic lineage tracing in the mouse model demonstrated that Sox 2 marks the competence of the continual lamina to generate teeth and all epithelial cell lineages of the serially added molars (Juuri et al. 2013).

Published data on the molecular regulation of successional tooth formation in reptiles and selected mammals have provided evidence that tooth morphogenesis and tooth replacement/ addition are regulated by the same signaling pathways. These include the WNT/ $\beta$-catenin, BMP, Shh, EDA, and FGF signaling pathways expressed in the intricate temporal and spatial patterns, which define the timing of individual tooth formation, size, shape, and position of all teeth (Balic and Thesleff 2015).

Thickening of the epithelium with inductive odontogenic potential marks the initiation of tooth development. By the time that placodes of primary teeth form, the inductive odontogenic potential has shifted to the mesenchyme. Serially added and replacement teeth develop from the budding of continual and successional lamina, respectively, after the initiation knot of the predecessor tooth has disappeared. What initiates the budding of the continual and successional laminae is not known. However, these teeth develop primary and secondary enamel knots, which indicates that their development is regulated by the same signaling cascades as in primary teeth (Jussila et al. 2014).

Wnt/ $\beta$-catenin signaling regulates tooth development at multiple stages and has been suggested as the key regulator of successional tooth formation. Inhibition of $\mathrm{Wnt} / \beta$-catenin signaling in the early epithelium leads to arrested tooth development at the lamina stage (Liu et al. 2008). Wnt activation throughout the ectoderm initiates multiple tooth buds and results in supernumerary teeth (Järvinen et al. 2006; Wang et al. 2009). The tip of the successional lamina in the reptiles is positive for Axin2 and Lef1, the Wnt activity reporter genes (Handrigan and Richman 2010). Mutations in the AXIN2 gene are related to tooth agenesis in humans (discussed later in the text). Another modulator of $\mathrm{Wnt} / \beta$-catenin signaling, Sostdc1 (Ectodin, Wise), is expressed at the tip of the successional lamina (Järvinen et al. 2009). Mice lacking Sostdc1 develop an extra incisor and molar, indicating that this gene plays an important role in determining the tooth number (Munne et al. 2009). Spatial restriction of Wnt activity to the tip of the successional lamina is thought to be caused by an exclusive and complementary domain of Hh signaling activity, which is absent from the successional lamina but instead emanates from 


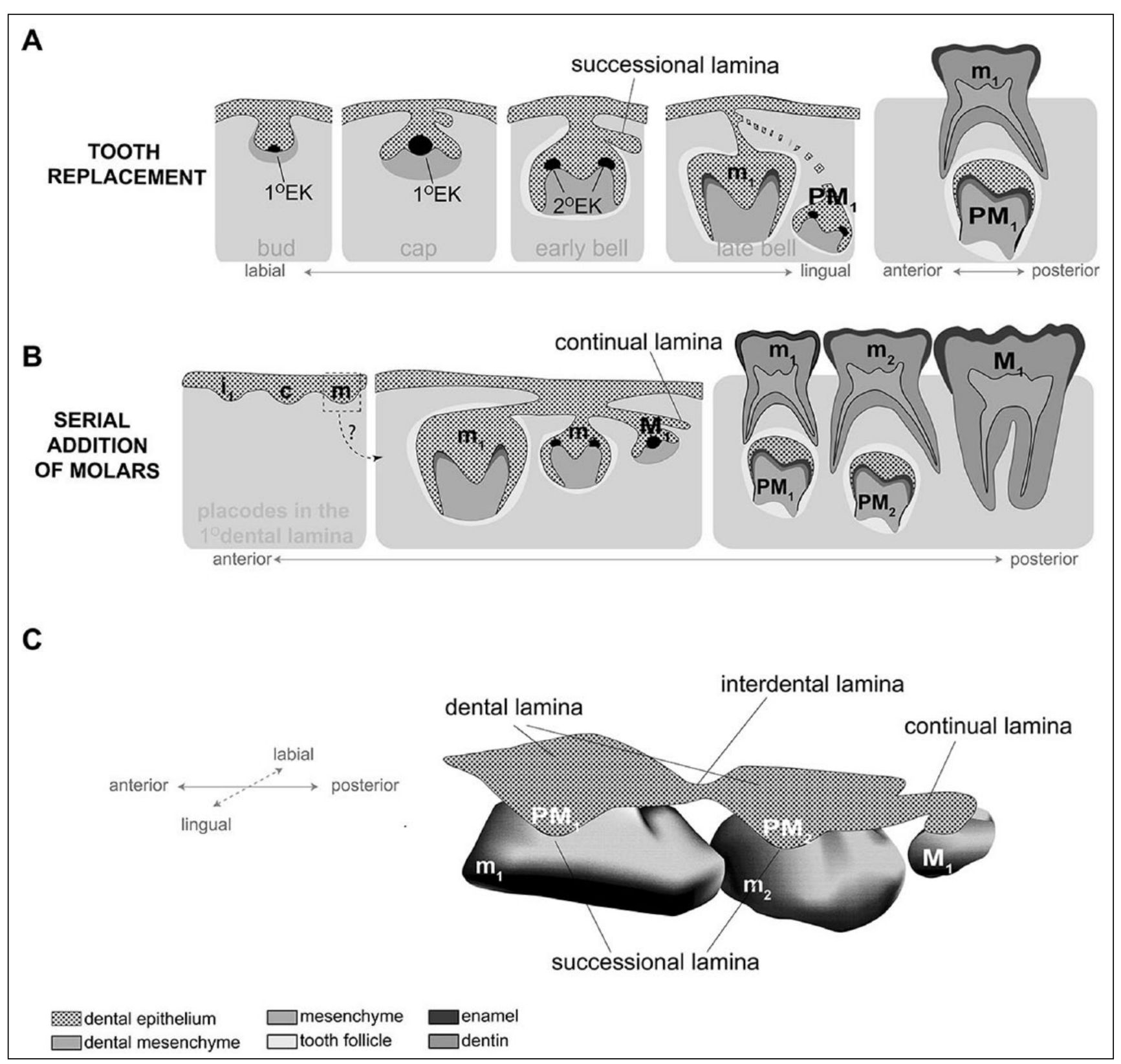

Figure 3. Development of the permanent dentition. (A) Permanent teeth, which replace the primary dentition, develop from successional lamina, which extends lingually from the dental lamina around the cap stage. (B) Permanent molars erupt posterior to primary dentition and are the only teeth in the permanent dentition that do not replace any primary teeth. It is not known whether these teeth develop from an independent placode within the primary dental lamina or are serially added from the continual lamina of the second primary molar. Therefore, it is still a matter of debate whether the permanent molars are part of the primary dentition or not. (C) Reconstruction of the human primary dentition adapted from Ooë (I98I) depicting primary molars and generation of the first permanent molar, all interconnected by interdental lamina. Initiation of permanent teeth from successional lamina is depicted. $2^{\circ} \mathrm{EK}$, secondary enamel knot; $m_{1}$, first primary molar; $m_{2}$, second primary molar; $M_{1}$, first permanent molar; $P M_{1}$, first premolar; $\mathrm{PM}_{2}$, second premolar.

the predecessor tooth (Ahn et al. 2010; Handrigan and Richman 2010). A similar pattern of Wnt/Hh activity is also observed in the mouse diastema that lacks teeth but not in the rest of the mouse dental epithelium (Ahn et al. 2010).

The mesenchyme surrounding the successional lamina bud is a source of various molecules that are potential key players in successional tooth formation. In particular, BMP2 and
BMP4 are expressed in the odontogenic condensed mesenchyme surrounding the tip of the successional lamina and were implied as positive modulators of Wnt signaling (Handrigan and Richman 2010; Jussila et al. 2014). Studies in mice have shown that induction of successional tooth formation depends on the correct spatial patterning of mesenchymal BMP signaling, which is regulated by the mesenchymal transcription 


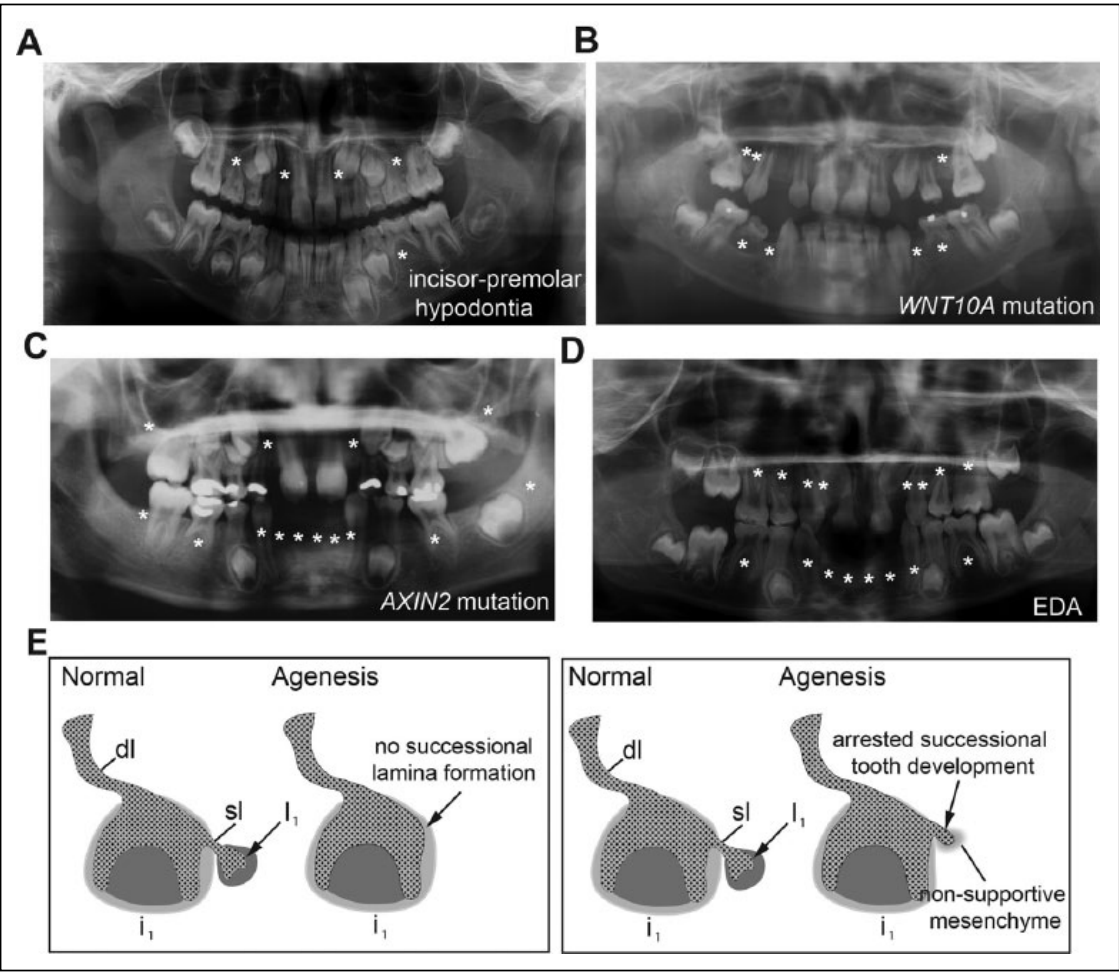

Figure 4. Panoramic radiographs from patients showing variable degrees of tooth agenesis. (A) Eight-year-old male with incisor-premolar hypodontia showing agenesis of maxillary lateral incisors, second maxillary premolars, and left mandibular second premolar. (B) Agenesis of maxillary right premolars and second left premolar and mandibular premolars in a 10 -y-old male with homozygous WNTIOA mutation. (C) Agenesis of right second permanent molars and left second or first permanent molars; mandibular incisors, canines, and second premolars; and maxillary lateral incisors in 8-y-old female with AXIN2 mutation. (D) A 7-y-old male with X-linked EDA showing agenesis of maxillary premolars, canines, and lateral incisors as well as permanent incisors, canines, and second premolars in mandible. (E) Schematics of possible mechanisms leading to tooth agenesis. (left) Successional lamina is not developing from the predecessor tooth due to depletion of the odontogenic potential in the dental lamina. (right) Successional lamina buds from the predecessor tooth but weakened or absent mesenchymal signals do not support further development of the successional tooth. Missing teeth marked by asterisks. Panels B and D courtesy of Elisa Ronkainenand; panel C courtesy of Laura Lammi. dl, dental lamina; i, first primary incisor;

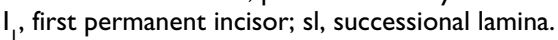

factor Osr2 (Zhang et al. 2009). Osr2 is expressed in the mesenchyme surrounding the tip of the successional lamina, as well as in interdental lamina (Jussila et al. 2014). Mice lacking Osr2 develop supernumerary teeth located on the lingual side, which is associated with the expansion of the $\mathrm{BMP}^{+}$odontogenic mesenchyme and resembles successional tooth formation (Zhang et al. 2009). Runx2 is another transcription factor expressed in the mesenchyme surrounding the tip of the successional lamina, and its heterozygotic loss of function leads to supernumerary tooth formation in humans (see later) and in budding of the dental lamina in mice (Jensen and Kreiborg 1990; Wang et al. 2005; Jussila et al. 2014). Mutations in the EDA pathway cause changes in the number of teeth in humans and mice, but gene expression analyses have not detected EDA-responsive cells expressing EDAR in the successional or interdental lamina. These cells, however, were found to contribute to the asymmetry of the primary dental lamina, where they were localized to the labial side (Pispa et al. 1999;
Mustonen et al. 2003; Richman and Handrigan 2011; Jussila et al. 2014). The following text describes in detail some human syndromes associated with changes in tooth number.

\section{Tooth Agenesis}

Tooth agenesis is one of the most common developmental anomalies in humans (Yin and Bian 2015). It is classified per the number of missing teeth to hypodontia, oligodontia, and anodontia. Hypodontia, an absence of 1 to 5 teeth (excluding third molars), is the most common. It occurs in primary dentition, with a prevalence between $0.1 \%$ and $1.5 \%$ and with no sex difference. In the permanent dentition, the prevalence of hypodontia is $3.5 \%$ to $7 \%$, and females are affected 1.5 times more than males (Brook et al. 2014). Oligodontia, an absence of $\geq 6$ teeth (excluding third molars), is relatively rare, with a prevalence of $0.3 \%$ (Bural et al. 2012). Anodontia, an absence of all teeth in one or both dentitions, occurs very rarely and only in some forms of ectodermal dysplasia (Nieminen 2009; Yin and Bian 2015).

Tooth agenesis can result from a failure in the initiation of tooth formation, reduced odontogenic potential of the dental lamina, or arrested development during early stage - for example, due to molecular change in the mesenchyme associated with the early tooth bud or the dental lamina of the successional teeth (Fig. 4). A gradual decrease of the odontogenic potential of dental lamina can explain why tooth agenesis most frequently affects the last tooth to develop within the tooth family. The most frequently missing tooth is the permanent third molar. At least 1 third molar is missing in $23 \%$ of people (Carter and Worthington 2015) and is therefore excluded from the classification above. Other commonly missing permanent teeth are the mandibular second premolars ( $3 \%$ to $4 \%$ ), the maxillary lateral incisors ( $1 \%$ to $2.5 \%$ ), and the maxillary second premolars ( $1 \%$ to $2 \%$; Brook et al. 2014).

Congenital tooth agenesis is typically an isolated anomaly present in otherwise normally developed individuals, but it has also been associated with $>150$ syndromic conditions. Hypodontia is most commonly associated with defects in other ectodermal organs on account of mutual genetic and cellular mechanisms that direct their development (Yin and Bian 2015). The distinction between isolated and syndromic tooth agenesis is not always straightforward, since many of the same genes that 
cause isolated tooth agenesis have been associated with syndromic tooth agenesis as well.

Genes associated with nonsyndromic isolated tooth agenesis include WNT10A, MSX1, PAX9, AXIN2, EDA, EDAR, EDARADD, LTBP3, LRP6, WNT1OB, GREM2, and SMOC. Up to $50 \%$ of tooth agenesis cases have been attributed to $W N T 10 A$ mutations (Fig. 4; Online Mendelian Inheritance in Man [OMIM] \#150400; Arte et al. 2013; Arzoo et al. 2014; Mues et al. 2014; Kantaputra 2015; Massink et al. 2015; Bergendal et al. 2016). Mutations in the Wnt inhibitor $A X I N 2$ cause a rare form of oligodontia in which permanent tooth formation is affected; the condition has also been associated with a predisposition to colorectal cancer (OMIM *604025; Lammi et al. 2004). Mutations in $L T B P 3$ and SMOC cause severe oligodontia in addition to other dental anomalies (OMIM \#601216, \#125400; Noor et al. 2009; Bloch-Zupan et al. 2011). Heterozygous lossof-function mutations in transcription factor $M S X 1$ or $P A X 9$ cause selective and severe tooth agenesis, which preferentially affects the posterior molars and second premolars, indicating an inhibition of successional tooth formation (OMIM \#106600, \#604625; Vastardis et al. 1996; Stockton et al. 2000).

The most common syndromes with tooth agenesis are ectodermal dysplasias affecting ectodermal organs, including teeth. The most common form is hypohidrotic ectodermal dysplasia caused by mutations in genes of the EDA pathway, including $E D A, E D A R, E D A R A D D$, and NEMO (Zonana et al. 2000). Hypohidrotic ectodermal dysplasia patients have abnormalities in several ectodermal organs and typically display thin and sparse hair, a reduced ability to sweat, dry mouth, and severe oligodontia (OMIM \#305100; Cluzeau et al. 2011). The remaining teeth are usually small and peg shaped (Fig. 4). MSX1 mutations may cause ectodermal dysplasia called Witkop syndrome and orofacial clefts (OMIM \#189500; Jumlongras et al. 2001). Mutations in WNT10A may lead to ectodermal dysplasia syndromes, such as odonto-onycho-dermal dysplasia (OMIM \#257980; Adaimy et al. 2007; Bergendal et al. 2016).

Other notable syndromic conditions often associated with tooth agenesis are Rieger syndrome and cleft syndromes. Rieger syndrome is caused by mutations in PITX2 resulting in abnormalities in the eye, umbilical anomalies, and dental abnormalities, including enamel hypoplasia and hypodontia affecting the incisor region (OMIM \#180500; Semina et al. 1996). Maxillary central incisors as well as primary teeth, which are rarely affected by tooth agenesis, might be missing. Van der Woude syndrome is caused by mutations in the interferon regulatory factor 6 (IRF6). It is characterized by the presence of lower lip pits, clefts in the lip and/or palate, and association with hypodontia (OMIM \#119300; Schinzel and Klausler 1986). In cleft syndrome patients, tooth agenesis may occur outside of and distant from the cleft side, mainly affecting the premolar region. These patients also have increased prevalence for supernumerary teeth. Furthermore, other dental anomalies in tooth shape can be observed in the lateral incisor region. The developmental vulnerability of the lateral incisor is likely explained by its localization at the cleft - that is, the fusion site of the medial nasal and maxillary processes (Hovorakova et al. 2006).

\section{Supernumerary Tooth Formation}

Supernumerary tooth formation, or hyperdontia, is not as common as hypodontia: the prevalence in the primary dentition is $0.2 \%$ to $0.8 \%$ and in the permanent dentition, $0.5 \%$ to $5.3 \%$, with geographic variations (Wang and Fan 2011). Similar to hypodontia, supernumerary teeth occur either as an isolated developmental anomaly or are related to syndromes with a genetic background.

Disturbances during the initiation and early stages of dental development may lead to formation of supernumerary tooth. However, the exact etiology remains unclear, and several theories have emerged to explain their occurrence. Dichotomy theory suggests that extra teeth form due to splitting of the successional dental lamina. Hyperproliferation of dental lamina or unresolved dental lamina fragments, as well as hyperinductive mesenchyme, are other possible causes of the supernumerary tooth formation (Wang and Fan 2011).

Based on studies on human embryos and syndromes, it seems that supernumerary teeth can form from the second generation of successional dental lamina or as continued serial addition of posterior molars (Fig. 5). Tooth replacement is associated with signaling pathway activities, and the arrest of tooth replacement to 1 round in most mammals may result from a change in the gene regulatory network responsible for the continuous supply of epithelial progenitors. Ooë (1981) provides morphologic evidence for the presence of the rudimentary successional lamina in the permanent human teeth, which implies that the potential to continuously generate teeth has been inhibited by a yet unknown molecular mechanism in humans. Sox 2 marks the odontogenic potential of dental lamina and is conserved during evolution in many species that replace their teeth. Most important, $S O X 2$ expression in human dental lamina suggests that a dormant capacity for sequential tooth formation exists in humans (Juuri et al. 2013). Interestingly, mutations in $S O X 2$ were associated with supernumerary teeth, suggesting that Sox 2 may have an inhibitory role in successional tooth formation (Numakura et al. 2010).

Mesiodens is the most common supernumerary tooth, with a prevalence of $0.15 \%$ to $1.9 \%$ in the general population (Van Buggenhout and Bailleul-Forestier 2008). It is located close to or at the midline and is conical and smaller than the neighboring incisor (Fig. 5). Rarely, 2 supernumerary teeth, mesiodentes, form in the midline (Fig. 5); however, it is thought that the mesiodens forms as an extra tooth from either side of the maxillary dental lamina. Furthermore, mesiodentes could represent additional primary teeth since they do not always appear to be connected to permanent teeth (Ooë 1981).

Mutations of only few genes have been identified as a cause of supernumerary tooth formation. Mutations in $R U N X 2$, a transcription factor essential for skeletal morphogenesis, cause cleidocranial dysplasia (OMIM \#119600). This is an autosomal dominant syndrome that affects bone development and leads to short stature, hypoplastic clavicles, open fontanelles, and supernumerary teeth (Fig. 5). The supernumerary teeth develop as new generations of replacement teeth 


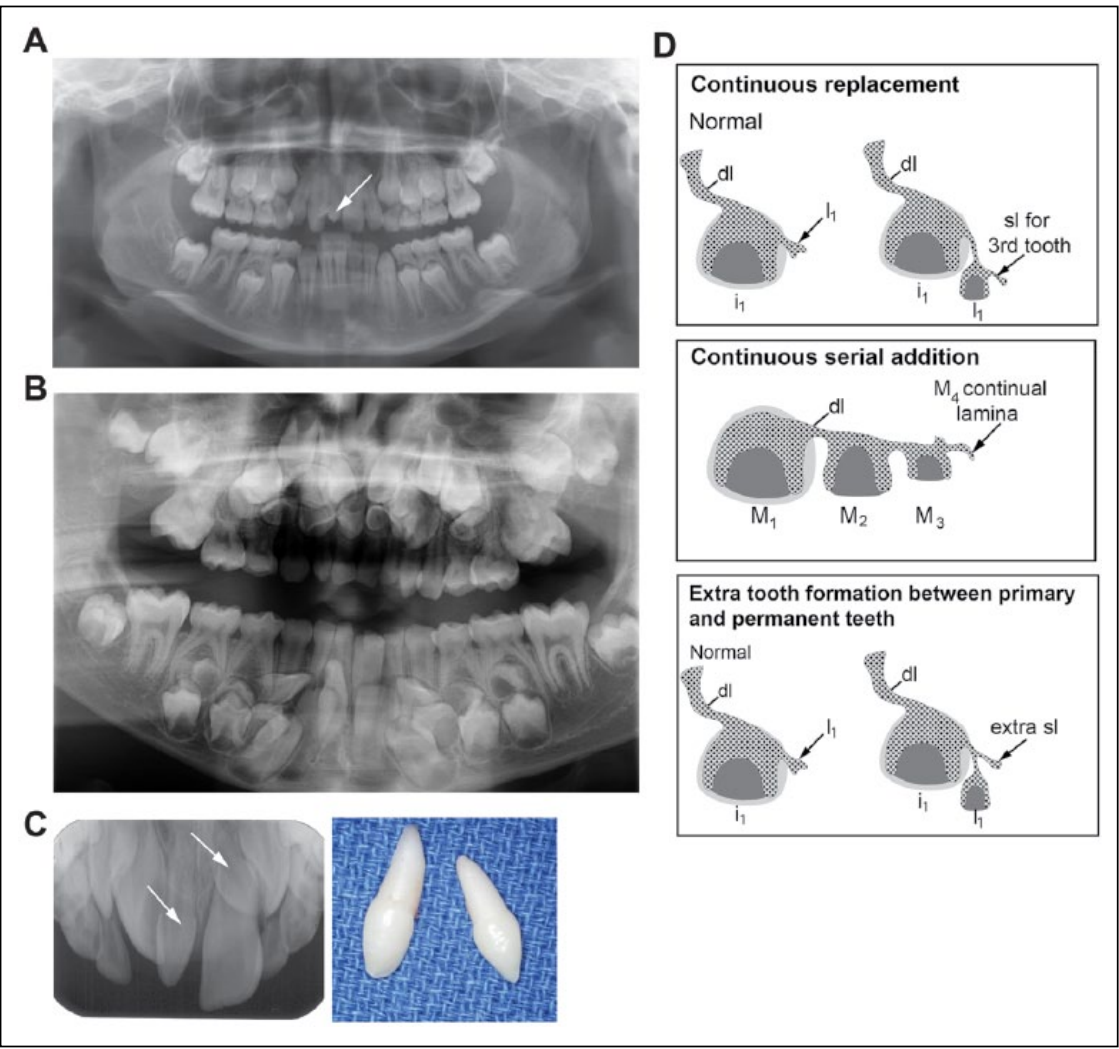

Figure 5. Panoramic radiographs showing isolated and syndromic supernumerary tooth formation. (A) Panoramic radiograph showing mesiodens (arrow) located between the maxillary central incisors in a 10-y-old female. (B) Nine-year-old male with cleidocranial dysplasia showing multiple supernumerary teeth. (C) Two supernumerary teeth (arrows), mesiodentes, between the maxillary central incisors in an X-ray and after extraction. (D) Schematics of the continued successional tooth formation. (above) Third generation of teeth starts to develop when second successional lamina is formed from the developing permanent tooth. (middle) Supernumerary permanent molars form by continued serial addition. The continual lamina forms in the distal end of the third molar and leads to the formation of fourth molar. (below) Supernumerary teeth may also arise in between the normal primary and permanent tooth. Panel A: courtesy of Johanna Kotilainen; panel B: courtesy of Tarja Siltanen; panel C: courtesy of Young Tse Kuah. dl, dental lamina; $i_{1}$, first primary incisor; $I_{1}$, first permanent incisor; $M_{1}, M_{2}, M_{3}, M_{4}$, first through fourth permanent molars; sl, successional lamina.

and as continued serial addition of molars (Fig. 5), both suggested to represent a third and even fourth dentition (Jensen and Kreiborg 1990). It is possible that the supernumerary teeth arise in between the normal primary and permanent tooth from ectopic signaling within the dental epithelium (Fig. 5). A similar dental phenotype is observed in Kreiborg-Pakistani syndrome, which is manifested by craniosynostosis, delayed tooth eruption, and supernumerary teeth and is caused by mutations in interleukin receptor IL11RA (OMIM *600939; Nieminen et al. 2011). Mutations in the $A P C$ gene (adenomatous polyposis coli) activate the Wnt pathway and cause human hereditary disorders called familial adenomatous polyposis or its variant Gardner syndrome (OMIM \#175100). Familial adenomatous polyposis leads to formation of potentially cancerous polyps in the intestine and supernumerary teeth, as well as odontomas containing multiple small teeth (Wang and Fan 2011).

\section{Tooth Size and Shape Variation}

Aberrations in tooth number, size, and shape are often linked. Hypodontia is frequently associated with smaller teeth when compared with that of the general population, often peg-shaped incisors and molars with fewer cusps. In contrast, dentitions with extra teeth are often associated with larger teeth and may show crown shape variations with additional cusps and grooves (Brook et al. 2014). Furthermore, double teeth and taurodontism are frequently detected malformations associated with tooth number variations.

Double teeth may originate by fusion of 2 tooth germs or by gemination when 2 teeth develop from 1 tooth bud (Fig. 6). The differentiation between fused and geminated double teeth is often difficult: if formed by fusion, the number of teeth is reduced, whereas if formed by gemination, the number of teeth present remain unchanged. Double teeth are more frequently detected in primary dentition (ranging from $0.5 \%$ to $4.5 \%$ ) than in permanent dentition (ranging from $0.1 \%$ to $0.3 \%$; Brook et al. 2014). The mechanisms of double-tooth formation are not fully understood, and basic principles can be suggested based on published data. In the primary dentition, double teeth may arise by fusion of 2 primary tooth germs or as a development of supernumerary primary tooth that forms by serial addition in the tooth family. During the formation of the permanent teeth, double teeth may arise from the duplication of the successional lamina (Fig. 6). A partial twinning of the successional lamina may result in 2 permanent teeth of almost the same size. If a supernumerary primary tooth is present, there is a strong likelihood that there will also be a supernumerary permanent tooth (Brook et al. 2014).

Taurodontism is a condition marked by enlarged pulp cavity and subsequent reduction of the root length. It is often associated with hypodontia, and it occurs in syndromes, especially those having an ectodermal defect (Puttalingaiah et al. 2014; Yang et al. 2015). In molars, taurodontism is seen as a vertically enlarged pulp cavity, with the floor of the pulp cavity moving toward the root apex resulting in shortened root proportion. The epithelial structure, known as Hertwig's epithelial root sheath (HERS), guides the root development. The apical shift of the root furcation in taurodontic teeth is due to the late timing or failure of HERS invagination (Yang et al. 2015). 


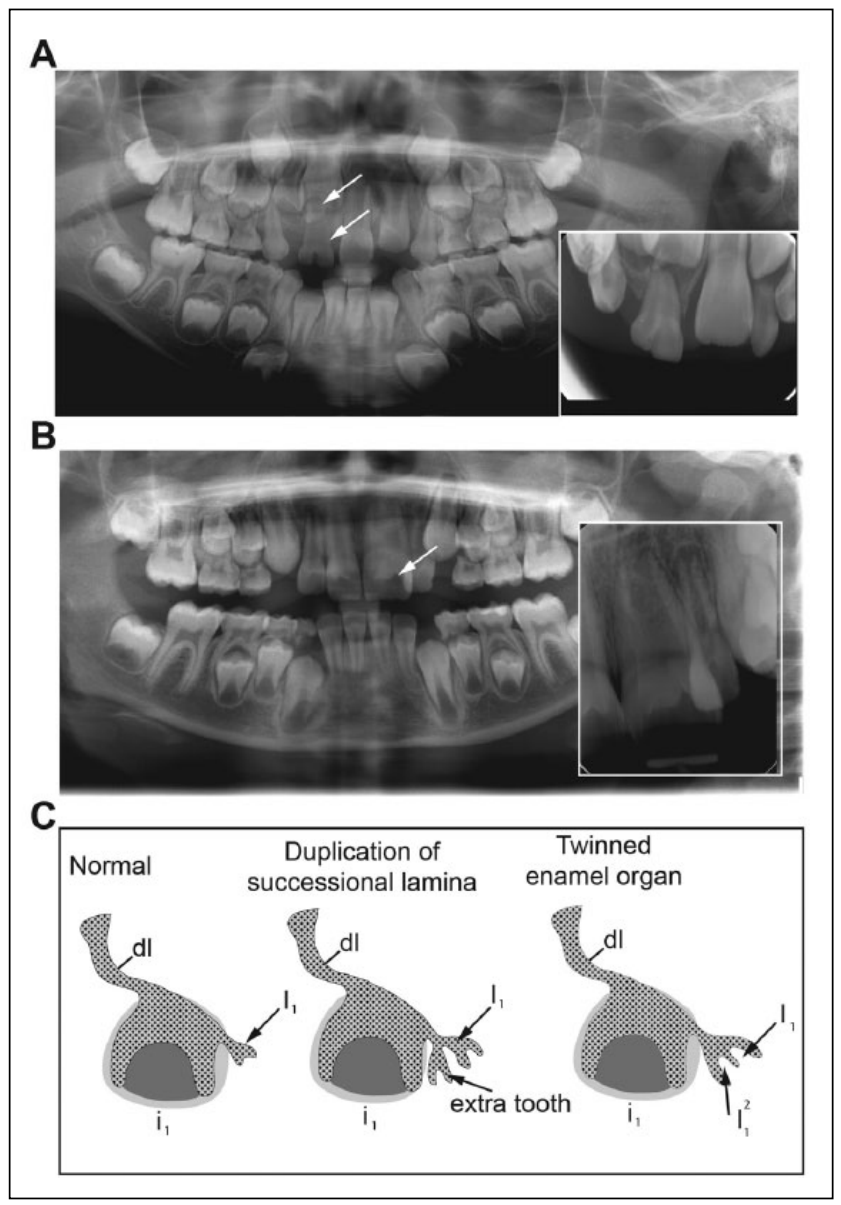

Figure 6. Panoramic radiographs showing duplicated primary and permanent maxillary central incisors. (A) An 8-y-old male with duplication of primary maxillary right central incisor (arrow), most likely formed by gemination of the primary incisor and a supernumerary tooth. In addition to the primary doubled incisor, a small supernumerary tooth is visible in the apical region of the primary tooth (arrow).

(B) A I I-y-old male with a permanent maxillary left central incisor formed by gemination of the permanent incisor and a supernumerary tooth (arrow). Tooth number remained unchanged. (C) Schematics of possible mechanisms of double-tooth formation. (middle) Duplication of successional lamina leads to formation of 2 joined teeth. (right) Splitting of the developing tooth bud leads to the formation of geminated tooth. $\mathrm{dl}$, dental lamina; $\mathrm{i}_{\mathrm{l}}$, first primary incisor; $\mathrm{I}_{1}$, first permanent incisor; $\mathrm{I}_{\mathrm{l}}{ }^{\text {, }}$ supernumerary permanent incisor.

Enamel knots play a central role in patterning of the tooth morphology. The Eda signal pathway has a specific role in the regulation of tooth signaling centers, since the Eda receptor Edar is specifically expressed in the initiation knots in tooth placodes as well as in the enamel knots (Mikkola and Thesleff 2003; Ahtiainen et al. 2016). Inhibition of the Eda pathway in mutant mouse models decreases the size of placodes and signaling centers, resulting in smaller tooth buds (Pispa et al. 1999; Ahtiainen et al. 2016) and the lack of the third molars or incisors, while the remaining teeth are usually smaller and have altered-shape crowns that are fused and lacking cusps (Pispa et al. 1999). Conversely, mice that overexpress Eda have large placodes and develop extra premolar-like teeth (Mustonen et al. 2003). Dental phenotypes are an outcome of complex interactions of genetic, epigenetic, and environmental factors. Deficient signaling from the dental placodes or from enamel knots, regulating the crown size and cusp patterning, can explain why tooth agenesis and morphological defects are linked.

\section{Conclusion}

Signaling pathways, which regulate the initiation and morphogenesis of primary and successional teeth, are shared among vertebrates, including fish, reptiles, and mammals. Therefore, various animal models can be utilized to study dental anomalies, which are one of the most common developmental anomalies in humans. Analyses of tooth development in various vertebrate species, together with genetic studies on patients, will improve our understanding of the etiology of the dental anomalies and lay the foundation for future biology-based treatments.

\section{Author Contributions}

E. Juuri and A. Balic, contributed to conception and design and drafted the manuscript. Both authors gave final approval and agree to be accountable for all aspects of the work.

\section{Acknowledgments}

We thank Professors Irma Thesleff and Joy Richman, Dr. Juuso Juuri, and Robert Leigh for critical reading of the manuscript. The authors received no financial support and declare no potential conflicts of interest with respect to the authorship and/or publication of this article.

\section{References}

Adaimy L, Chouery E, Megarbane H, Mroueh S, Delague V, Nicolas E, Belguith H, de Mazancourt P, Megarbane A. 2007. Mutation in WNT10A is associated with an autosomal recessive ectodermal dysplasia: the odontoonycho-dermal dysplasia. Am J Hum Genet. 81(4):821-828.

Ahn Y, Sanderson BW, Klein OD, Krumlauf R. 2010. Inhibition of Wnt signaling by Wise (Sostdc1) and negative feedback from Shh controls tooth number and patterning. Development. 137(19):3221-3231.

Ahtiainen L, Uski I, Thesleff I, Mikkola ML. 2016. Early epithelial signaling center governs tooth budding morphogenesis. J Cell Biol. 214(6):753-767.

Arte S, Parmanen S, Pirinen S, Alaluusua S, Nieminen P. 2013. Candidate gene analysis of tooth agenesis identifies novel mutations in six genes and suggests significant role for WNT and EDA signaling and allele combinations. PLoS One. 8(8):e73705.

Arzoo PS, Klar J, Bergendal B, Norderyd J, Dahl N. 2014. Wnt10a mutations account for $(1 / 4)$ of population-based isolated oligodontia and show phenotypic correlations. Am J Med Genet A. 164(2):353-359.

Balic A, Thesleff I. 2015. Tissue interactions regulating tooth development and renewal. Curr Top Dev Biol. 115:157-186.

Bergendal B, Norderyd J, Zhou X, Klar J, Dahl N. 2016. Abnormal primary and permanent dentitions with ectodermal symptoms predict WNT10A deficiency. BMC Med Genet. 17(1):88.

Bloch-Zupan A, Jamet X, Etard C, Laugel V, Muller J, Geoffroy V, Strauss JP, Pelletier V, Marion V, Poch O, et al. 2011. Homozygosity mapping and candidate prioritization identify mutations, missed by whole-exome sequencing, in SMOC2, causing major dental developmental defects. Am J Hum Genet. 89(6): 773-781

Brook AH, Jernvall J, Smith RN, Hughes TE, Townsend GC. 2014. The dentition: the outcomes of morphogenesis leading to variations of tooth number, size and shape. Aust Dent J. 59 Suppl 1:131-142.

Bural C, Oztas E, Ozturk S, Bayraktar G. 2012. Multidisciplinary treatment of non-syndromic oligodontia. Eur J Dent. 6(2):218-226.

Carter K, Worthington S. 2015. Morphologic and demographic predictors of third molar agenesis: a systematic review and meta-analysis. J Dent Res. 94(7):886-894. 
Cluzeau C, Hadj-Rabia S, Jambou M, Mansour S, Guigue P, Masmoudi S, Bal E, Chassaing N, Vincent MC, Viot G, et al. 2011. Only four genes (EDA1, EDAR, EDARADD, and WNT10A) account for $90 \%$ of hypohidrotic/anhidrotic ectodermal dysplasia cases. Hum Mutat. 32(1):70-72.

Gaete M, Tucker AS. 2013. Organized emergence of multiple-generations of teeth in snakes is dysregulated by activation of Wnt/beta-catenin signalling. PLoS One. 8(9):e74484.

Handrigan GR, Leung KJ, Richman JM. 2010. Identification of putative dental epithelial stem cells in a lizard with life-long tooth replacement. Development. 137(21):3545-3549.

Handrigan GR, Richman JM. 2010. A network of Wnt, hedgehog and BMP signaling pathways regulates tooth replacement in snakes. Dev Biol. 348(1): 130-141.

Hovorakova M, Lesot H, Peterkova R, Peterka M. 2006. Origin of the deciduous upper lateral incisor and its clinical aspects. J Dent Res. 85(2):167-171.

Hovorakova M, Lesot H, Vonesch JL, Peterka M, Peterkova R. 2007. Early development of the lower deciduous dentition and oral vestibule in human embryos. Eur J Oral Sci. 115(4):280-287.

Huysseune A, Witten PE. 2006. Developmental mechanisms underlying tooth patterning in continuously replacing osteichthyan dentitions. J Exp Zool B Mol Dev Evol. 306(3):204-215.

Järvinen E, Salazar-Ciudad I, Birchmeier W, Taketo MM, Jernvall J, Thesleff I. 2006. Continuous tooth generation in mouse is induced by activated epithelial Wnt/beta-catenin signaling. Proc Natl Acad Sci U S A. 103(49):18627-18632.

Järvinen E, Tummers M, Thesleff I. 2009. The role of the dental lamina in mammalian tooth replacement. J Exp Zool B Mol Dev Evol. 312(4):281-291

Järvinen E, Valimaki K, Pummila M, Thesleff I, Jernvall J. 2008. The taming of the shrew milk teeth. Evol Dev. 10(4):477-486.

Jensen BL, Kreiborg S. 1990. Development of the dentition in cleidocranial dysplasia. J Oral Pathol Med. 19(2):89-93.

Jernvall J, Thesleff I. 2012. Tooth shape formation and tooth renewal: evolving with the same signals. Development. 139(19):3487-3497.

Jumlongras D, Bei M, Stimson JM, Wang WF, DePalma SR, Seidman CE, Felbor U, Maas R, Seidman JG, Olsen BR. 2001. A nonsense mutation in MSX1 causes Witkop syndrome. Am J Hum Genet. 69(1):67-74.

Jussila M, Crespo Yanez X, Thesleff I. 2014. Initiation of teeth from the dental lamina in the ferret. Differentiation. 87(1-2):32-43.

Juuri E, Jussila M, Seidel K, Holmes S, Wu P, Richman J, Heikinheimo K, Chuong CM, Arnold K, Hochedlinger K, et al. 2013. Sox2 marks epithelial competence to generate teeth in mammals and reptiles. Development. 140(7):1424-1432

Kantaputra PN, Kaewgahya M, Hatsadaloi A, Vogel P, Kawasaki K, Ohazama A, Ketudat Cairns JR. 2015. GREMLIN 2 mutations and dental anomalies. J Dent Res. 94(12):1646-1652.

Lammi L, Arte S, Somer M, Jarvinen H, Lahermo P, Thesleff I, Pirinen S, Nieminen P. 2004. Mutations in AXIN2 cause familial tooth agenesis and predispose to colorectal cancer. Am J Hum Genet. 74(5):1043-1050.

Laurikkala J, Mikkola ML, James M, Tummers M, Mills AA, Thesleff I. 2006. P63 regulates multiple signalling pathways required for ectodermal organogenesis and differentiation. Development. 133(8):1553-1563.

Liu F, Chu EY, Watt B, Zhang Y, Gallant NM, Andl T, Yang SH, Lu MM, Piccolo S, Schmidt-Ullrich R, et al. 2008. Wnt/beta-catenin signaling directs multiple stages of tooth morphogenesis. Dev Biol. 313(1):210-224.

Martin KJ, Rasch LJ, Cooper RL, Metscher BD, Johanson Z, Fraser GJ. 2016. Sox $2+$ progenitors in sharks link taste development with the evolution of regenerative teeth from denticles. Proc Natl Acad Sci U S A. 113(51):14769-14774.

Massink MP, Creton MA, Spanevello F, Fennis WM, Cune MS, Savelberg SM, Nijman IJ, Maurice MM, van den Boogaard MJ, van Haaften G. 2015. Loss-of-function mutations in the WNT co-receptor LRP6 cause autosomal-dominant oligodontia. Am J Hum Genet. 97(4):621-626.

Mikkola ML, Thesleff I. 2003. Ectodysplasin signaling in development. Cytokine Growth Factor Rev. 14(3-4):211-224.

Mues G, Bonds J, Xiang L, Vieira AR, Seymen F, Klein O, D'Souza RN. 2014. The WNT10A gene in ectodermal dysplasias and selective tooth agenesis. Am J Med Genet A. 164(10):2455-2460.

Munne PM, Tummers M, Jarvinen E, Thesleff I, Jernvall J. 2009. Tinkering with the inductive mesenchyme: Sostdc1 uncovers the role of dental mesenchyme in limiting tooth induction. Development. 136(3):393-402.

Mustonen T, Pispa J, Mikkola ML, Pummila M, Kangas AT, Pakkasjarvi L, Jaatinen R, Thesleff I. 2003. Stimulation of ectodermal organ development by Ectodysplasin-A1. Dev Biol. 259(1):123-136.

Nakamura T, Unda F, de-Vega S, Vilaxa A, Fukumoto S, Yamada KM, Yamada Y. 2004. The Krüppel-like factor epiprofin is expressed by epithelium of developing teeth, hair follicles, and limb buds and promotes cell proliferation. J Biol Chem. 279(1):626-634.

Nieminen P. 2009. Genetic basis of tooth agenesis. J Exp Zool B Mol Dev Evol. 312(4):320-342

Nieminen P, Morgan NV, Fenwick AL, Parmanen S, Veistinen L, Mikkola ML, van der Spek PJ, Giraud A, Judd L, Arte S, et al. 2011. Inactivation of IL11 signaling causes craniosynostosis, delayed tooth eruption, and supernumerary teeth. Am J Hum Genet. 89(1):67-81

Noor A, Windpassinger C, Vitcu I, Orlic M, Rafiq MA, Khalid M, Malik MN, Ayub M, Alman B, Vincent JB. 2009. Oligodontia is caused by mutation in LTBP3, the gene encoding latent TGF-beta binding protein 3. Am J Hum Genet. 84(4):519-523

Numakura C, Kitanaka S, Kato M, Ishikawa S, Hamamoto Y, Katsushima Y, Kimura T, Hayasaka K. 2010. Supernumerary impacted teeth in a patient with SOX2 anophthalmia syndrome. Am J Med Genet A. 152(9): $2355-2359$.

Ooë T. 1981. Human tooth and dental arch development. Tokyo (Japan): Ishiyaku Publishers Inc.

Peterkova R, Hovorakova M, Peterka M, Lesot H. 2014. Three-dimensional analysis of the early development of the dentition. Aust Dent J. 59 Suppl $1: 55-80$.

Pispa J, Jung HS, Jernvall J, Kettunen P, Mustonen T, Tabata MJ, Kere J, Thesleff I. 1999. Cusp patterning defect in tabby mouse teeth and its partial rescue by FGF. Dev Biol. 216(2):521-534.

Popa EM, Anthwal N, Tucker AS. 2016. Complex patterns of tooth replacement revealed in the fruit bat (Eidolon helvum). J Anat. 229(6):847-856.

Putnova I, Dosedelova H, Bryja V, Landova M, Buchtova M, Stembirek J. 2017. Angled growth of the dental lamina is accompanied by asymmetrical expression of the WNT pathway receptor frizzled 6. Front Physiol. 8:29.

Puttalingaiah VD, Agarwal P, Miglani R, Gupta P, Sankaran A, Dube G. 2014. Assessing the association of taurodontism with numeric dentition anomalies in an adult central indian population. J Nat Sci Biol Med. 5(2):429-433.

Richman JM, Handrigan GR. 2011. Reptilian tooth development. Genesis. 49(4):247-260.

Schinzel A, Klausler M. 1986. The Van der Woude syndrome (dominantly inherited lip pits and clefts). J Med Genet. 23(4):291-294.

Semina EV, Reiter R, Leysens NJ, Alward WL, Small KW, Datson NA, Siegel-Bartelt J, Bierke-Nelson D, Bitoun P, Zabel BU, et al. 1996. Cloning and characterization of a novel bicoid-related homeobox transcription factor gene, RIEG, involved in Rieger syndrome. Nat Genet. 14(4):392-399.

Stembírek J, Buchtová M, Král T, Matalová E, Lozanoff S, Míšek I. 2010. Early morphogenesis of heterodont dentition in minipigs. Eur J Oral Sci. 118(6):547-558

Stockton DW, Das P, Goldenberg M, D'Souza RN, Patel PI. 2000. Mutation of PAX9 is associated with oligodontia. Nat Genet. 24(1):18-19.

Van Buggenhout G, Bailleul-Forestier I. 2008. Mesiodens. Eur J Med Genet. 51(2):178-181.

Vastardis H, Karimbux N, Guthua SW, Seidman JG, Seidman CE. 1996. A human MSX1 homeodomain missense mutation causes selective tooth agenesis. Nat Genet. 13(4):417-421.

Wang XP, Aberg T, James MJ, Levanon D, Groner Y, Thesleff I. 2005. Runx2 (Cbfa1) inhibits Shh signaling in the lower but not upper molars of mouse embryos and prevents the budding of putative successional teeth. J Dent Res. 84(2):138-143.

Wang XP, Fan J. 2011. Molecular genetics of supernumerary tooth formation. Genesis. 49(4):261-277.

Wang XP, O'Connell DJ, Lund JJ, Saadi I, Kuraguchi M, Turbe-Doan A, Cavallesco R, Kim H, Park PJ, Harada H, et al. 2009. Apc inhibition of Wnt signaling regulates supernumerary tooth formation during embryogenesis and throughout adulthood. Development. 136(11):1939-1949.

Yang J, Wang SK, Choi M, Reid BM, Hu Y, Lee YL, Herzog CR, Kim-Berman $\mathrm{H}$, Lee M, Benke PJ, et al. 2015. Taurodontism, variations in tooth number, and misshapened crowns in Wnt10a null mice and human kindreds. Mol Genet Genomic Med. 3(1):40-58.

Yin W, Bian Z. 2015. The gene network underlying hypodontia. J Dent Res. 94(7):878-885.

Zhang Z, Lan Y, Chai Y, Jiang R. 2009. Antagonistic actions of Msx1 and Osr2 pattern mammalian teeth into a single row. Science. 323(5918):1232-1234.

Zonana J, Elder ME, Schneider LC, Orlow SJ, Moss C, Golabi M, Shapira SK, Farndon PA, Wara DW, Emmal SA, et al. 2000. A novel X-linked disorder of immune deficiency and hypohidrotic ectodermal dysplasia is allelic to incontinentia pigmenti and due to mutations in IKK-gamma (NEMO). Am J Hum Genet. 67(6):1555-1562. 